\title{
Modulation of dopamine transporter functions by protein kinase C
}

\author{
Sang-Hun Lee ${ }^{1,2}$, Jai-Kyung Koh ${ }^{1}$ \\ Joong-Soo Han ${ }^{1}$, Young-Mi Kim ${ }^{1}$ \\ Jang-Hyuk Lee ${ }^{1}$ and Yong-Sung Lee ${ }^{1}$ \\ 1 Department of Biochemistry, College of Medicine, Hanyang University, \\ Seoul 133-791, Korea \\ 2 Corresponding author
}

\section{Accepted 20 May 1996}

Abbreviations: DAT, dopamine transporter; PMA, phorbol 12-myristrate 13acetate; MPP+, 1-methyl-4-phenylpyridinium; PKC, protein kinase C; PKA, cAMP-dependent protein kinase $\mathrm{A}$; CaM kinase II, $\mathrm{Ca}^{2+}$-calmodulindependent kinase II; DMEM, Dulbecco's modified Eagle medium; CFT, $2 \beta$ carbomethoxy-33-(4-fluorophenyl) tropane; CNS, central nervous system

\begin{abstract}
The effects of phosphorylation on the functions of the bovine dopamine transporter (DAT) expressed in CV-1 cells were investigated. The cells expressing DAT stably were prepared by transfection of CV-1 cells (monkey kidney cell line) with plasmid pRc/CMV-DAT which is an expression vector $\mathrm{pRc} / \mathrm{CMV}$-based plasmid containing bovine DAT cDNA (Usdin et al., 1991). DAT functional assays followed the preincubations of DAT expressing cells with various modulators of protein kinases, such as phorbol 12-myristrate 13-acetate (PMA), staurosphorin, calphostin C, forskolin, and EGTA, on the concentration- or time-dependent manners. Dopamine uptake into DAT expressing cells was severely decreased by PMA pretreatment, and increased by staurosphorin or calphostin $C$. Similar effects were observed on the uptakes of 1methyl-4-phenylpyridinium (MPP ${ }^{+}$) into DATexpressing cells. However, DAT functions were not altered by forskolin or EGTA. These results suggest that the functions of DAT are modulated by protein kinase $\mathrm{C}$ (PKC).
\end{abstract}

Keywords: dopamine transporter, modulation, phosphorylation, protein kinase $\mathrm{C}$

\section{Introduction}

Dopamine transporter (DAT) is a highly specialized membrane-spanning protein that aids in terminating dopaminergic neurotransmission by sodium-dependent reuptake of dopamine into presynaptic neurons (Iversen, 1971; Horn, 1990; Shimada et al., 1991; Uhl, 1992; Uhl and Hartig, 1992). This transporter also acts as a gate for dopaminergic neurotoxins such as 1methyl-4-phenylpyridinium $\left(\mathrm{MPP}^{+}\right)$(Snyder and D'Amato; 1986, Uhl, 1990; Kitayama et al., 1992a), and the recognition sites for various psychotropic drugs including cocaine (Shimada et al., 1991; Usdin et al., 1991).

All the species homologues of the DAT (rat, bovine, and human) possess consensus sites for phosphorylation by CAMP-dependent protein kinase $A$ (PKA), $\mathrm{Ca}^{2+}$-calmodulin-dependent kinase II (CaM kinase II) and protein kinase $C$ (PKC). The existence of putative phosphorylation sites indicates that the functions of DAT may be regulated by protein kinases or phosphatases.

The involvements of PKC and PKA in downregulation of receptors for neurotransmitters have been well established, and several data have also suggested the possibilities that the functions of neurotransmitter transporters are regulated by protein kinases. The $5-\mathrm{HT}$ transporter activity of human placental choriocarcinoma cells has been shown to be modulated by various protein kinase activators (Cool et al., 1991). It has been suggested that glutamate transporter activity is increased in cultured glial cells after incubation of the cells with phorbol esters (Casado et al., 1991), and this stimulation of activity by phorbol esters is due to a direct phosphorylation of the transporter by PKC (Casado et al., 1993). The involvement of PKA in gamma-aminobutyric acid (GABA) transporter regulation has been also suggested (Tian et al., 1994). Here, we demonstrate the possible implications of phosphorylation by $\mathrm{PKC}$ in the regulation of DAT actions.

\section{Materials and Methods}

\section{Preparation of DAT-expressing cell line}

To obtain the cells, which stably express DAT and in which the phosphorylation effects on the functions of DAT could be studied, CV-1 cells (monkey kidney cell line) were transfected with plasmid $p R c / C M V-D A T$ which is an expression vector $\mathrm{pRc} / \mathrm{CMV}$-based plasmid containing bovine DAT cDNA (Usdin et al., 1991). The transfection was carried out using liposome (Felgner et al., 1987). The Lipofectin reagent (10 $\mu$, GIBCO BRL, 
Gaitherburg, MA) and DNA (2 $\mu \mathrm{g})$ were mixed to form complexes. These DNA-Lipofectin complexes were added on CV-1 cells ( $1-2 \times 10^{5}$ cells) plated in $60-\mathrm{mm}$ tissue culture plate and allowed to be introduced into cells for $24 \mathrm{~h}$. After then, transfectants were selected by growing cells in G418 (geneticin, $400 \mu \mathrm{g} / \mathrm{ml}$, Gibco BRL, Gaitherburg, MA)-containing medium. Most of the transfectant colonies expressed the functional DAT as seen by acquisition of functional dopamine uptake activity. The cells showing the highest dopamine uptake activity were used in the following experiments.

\section{Cell culture}

The CV-1 cells were cultured at $5 \% \mathrm{CO}_{2}$ in Dulbecco's modified Eagle medium (DMEM) supplemented with $10 \%$ fetal bovine serum and antibiotics. The culture conditions of $\mathrm{pRc} / \mathrm{CMV}$-DAT -transfectants were identical to those of CV-1 cells, except that $250 \mu \mathrm{g} / \mathrm{ml}$ of G418 were supplemented to the medium.

\section{Functional analyses of DAT}

1-2 $\times 10^{5}$ DAT-expressing cells were plated in 24-well plate. After $24 \mathrm{~h}$, the cells were washed with uptake buffer (25 mM Hepes, $\mathrm{pH} 7.4 / 125 \mathrm{mM} \mathrm{NaCl} / 4.8 \mathrm{mM}$ $\mathrm{KCl} / 1.2 \mathrm{mM} \mathrm{KH}_{2} \mathrm{PO}_{4} / 1.3 \mathrm{mM} \mathrm{CaCl}_{2} / 1.2 \mathrm{mM} \mathrm{MgSO}_{4} / 5.6$ $\mathrm{mM}$ glucose/1 $\mathrm{mM}$ 'sodium ascorbate/10 $\mu \mathrm{M}$ pargyline), incubated in the uptake buffer for $10 \mathrm{~min}$ at $37^{\circ} \mathrm{C}$ and then treated with $100 \mathrm{nM}\left[{ }^{3} \mathrm{H}\right]$ dopamine $(51 \mathrm{Ci} / \mathrm{mmol}$, Amersham, England) or $10 \mathrm{nM}\left[{ }^{3} \mathrm{H}\right] \mathrm{MPP}^{+}(83 \mathrm{Ci} / \mathrm{mmol}$, Dupont-New England Nuclear, Boston, MA) for $10 \mathrm{~min}$ at $37^{\circ} \mathrm{C}$. The uptake reactions were terminated by adding ice-cold uptake buffer and three washes with ice-cold uptake buffer were followed. Cells were solubilzed in $0.5 \mathrm{M} \mathrm{NaOH}$, and radioactivity was assessed by liquid scintillation spectroscopy. The binding of the cocaine congener, $\left[{ }^{3} \mathrm{H}\right] 2 \beta$-carbomethoxy$3 \beta$-(4-fluorophenyl)tropane $\left({ }^{3} \mathrm{H}\right] \mathrm{CFT}$, also designated $\left[{ }^{3} \mathrm{H}\right]$ WIN35,428) to DATs on intact cell membranes was determined by incubating cells with the same buffer containing $10 \mathrm{nM}\left[{ }^{3} \mathrm{H}\right] \mathrm{CFT}(87 \mathrm{Ci} / \mathrm{mmol}$, Dupont-New England Nuclear, Boston, MA) for $120 \mathrm{~min}$ at $4^{\circ} \mathrm{C}$. The parallel incubations using the identical numbers of untransfected CV-1 cells were done to provide estimates of nonspecific uptakes or bindings.

To obtain informations as to the effects of phosphorylation on DAT functions, the uptake (or binding) activities were assessed by pretreating the DAT-expressing cells at $37^{\circ} \mathrm{C}$ on the concentration- or time-course manners with each of phorbol 12-myristrate 13-acetate (PMA, a PKC activator) (Castagna et al., 1982; Nishizuka, 1984; Brasseur et al., 1985), staurosphorine (a nonspecific protein kinase inhibitor), calphostin C (a specific PKC inhibitor) (Kobayashi et al., 1989), forskolin (a PKA activator), and EGTA ( $\mathrm{Ca}^{2+}$ chelating agent, a inhibitor of CaM kinase II). PMA was phurchased from Calbiochem (La Jolla, CA), and staurosphorin, calphostin $\mathrm{C}$ and forskolin were purchased from Sigma (St. Louis, MO).

\section{Results}

CV-1 cells, transfected with pRc/CMV-DAT, stably expressed a high affinity DAT under normal conditions with no experimental manipulation. Stable transfectant cells showed 30-50-folds higher dopamine uptake than nontransfectants in dopamine uptake assays. Most of the general characteristics of this transporter were similar to those of DATs, reported in other papers. $K_{m}$ of dopamine transporting $(991.6 \mathrm{nM})$ is nearly identical to that of expessed-rat DAT (885 nM, Kilty et al., 1991), and inhibitory patterns of dopamine transporting by various psychotropic drugs including cocaine analog are similar to expressed-rat or synaptosomal DAT. However, $\mathrm{MPP}^{+}$uptake activity of expressed-bovine DAT was significantly lesser than that of expressed-rat

Table 1. Effect of drugs related with protein phosphorylation on DAT functions in CV-1 cells expressing pRc/CMV-DAT. Cells were pre-incubated in the presence of each drugs for $10 \mathrm{~min}$ at $37^{\circ} \mathrm{C}$ and followed by uptake assays for $10 \mathrm{~min}$ $\left(\left[{ }^{3} \mathrm{H}\right]\right.$ dopamin uptake) or for $1 \mathrm{~h}\left({ }^{3} \mathrm{H}\right] \mathrm{MPP}{ }^{+}$uptake $)$at $37^{\circ} \mathrm{C}$. Data represent the mean \pm S.D. of three experiments.

\begin{tabular}{lrccc}
\hline & \multicolumn{3}{c}{$\left[{ }^{3} \mathrm{H}\right]$ Dopamine uptake } & \multicolumn{2}{c}{$\left[{ }^{3} \mathrm{H}\right] \mathrm{MPP} \mathrm{P}^{+}$uptake } \\
\cline { 2 - 5 } & $\mathrm{fmol} / 10^{5}$ cell/10 min & $(\%$ of control $)$ & fmol/10 ${ }^{5}$ cell/h & (\% of control) \\
\hline Control & $65.25 \pm 4.34$ & $(100)$ & $4.87 \pm 0.38$ & $(100)$ \\
PMA $(1 \mu \mathrm{M})$ & $20.56 \pm 0.87$ & $(31.5)$ & $2.79 \pm 0.49$ & $(57.2)$ \\
Staurosphorin $(5 \mu \mathrm{M})$ & $100.01 \pm 4.10$ & $(153.2)$ & - & \\
Calphostin C $(0.5 \mathrm{mM})$ & $112.29 \pm 11.52$ & $(170.1)$ & $6.81 \pm 0.54$ & $(139.8)$ \\
PMA + Staurosphorin & $93.48 \pm 11.43$ & $(143.2)$ & - & \\
Forskolin $(100 \mu \mathrm{M})$ & $67.62 \pm 5.09$ & $(103.6)$ & $4.13 \pm 0.18$ & $(84.8)$ \\
EGTA $(4 \mathrm{mM})$ & $70.49 \pm 12.49$ & $(108.0)$ & $4.55 \pm 0.23$ & $(93.4)$ \\
\hline
\end{tabular}


DAT (Kitayama et al., 1992a, 1993), and no CFT binding activity was seen. Therefore, the effect of phosphorylation on CFT-binding of DAT could not be done.

Table 1 shows that PKC, but not PKA nor CaM kinase II, modulate the uptake of dopamine and $\mathrm{MPP}^{+}$. Dopamine uptake was reduced by treatment of PMA, and increased when staurosphorine or calphostin $C$ was added. PMA- effects on MPP ${ }^{+}$uptakes displayed a similar pattern. A dose-response relationships for the effects of PMA on the DAT action demonstrate that dopamine uptake was decreased with increasing concentrations of $P M A$, reaching a plateau at approximately $1 \mu \mathrm{M}$ of PMA (Figure 1), but increased infinitely with increasing doses of calphostin C $(100 \mu \mathrm{M}$ - $20 \mathrm{mM}$ ). However, no changes were seen by forskolin in the range of concentrations studied $(10 \mathrm{nM}-100 \mu \mathrm{M})$ (data not shown). The time-effects of preincubation with either PMA or calphostin $C$ on dopamine uptake were shown in Figure 2.

\section{Discussion}

It is well known that PKC-mediated phosphorylation plays an important role in the regulation of various receptors for neurotransmitters in the CNS. The existence of putative PKC sites on DAT make it possible to presume the involvement of PKC-mediated phosphorylation in the regulation of DAT functions. The current results show that the functions of DAT are modulated by specific activator and inhibitors of PKC, but not by those of PKA or CaM-kinase II, suggesting that the functions of DAT may be modulated by PKCmediated phosphorylation. PKC-mediated reductions in dopamine uptake would be expected to enhance the synaptic efficacy of release of a fixed amount of dopamine in vivo. Although the current studies cannot directly demonstrate such functions in the dopamine nerve terminals in brain, they do document that such effects are possible

Kitayama reported that efficiencies of dopamine, $\mathrm{MPP}^{+}$transport and cocaine binding were differentially altered by the site-directed mutations on some putative transmembrane domains of DAT (Kitayama et al., 1992b; Kitayama et al., 1993). Boja and his colleagues presented controversial finding that more than one cocaine binding site exits in a single dopamine transporter (Boja et al., 1992). These two findings suggest the DAT sites recognizing dopamine, neurotoxin $\mathrm{MPP}^{+}$, and cocaine may not be located in an identical position, and their mechanisms of actions or regulations can be different, even though they are closely related. Therefore, we tried to find any differences of regulations between the adverse functions (MPP ${ }^{+}$uptake and cocaine binding) and normal physiologic function (dopamine uptake) of DAT by protein phosphorylation. If it turn out to be true, the different regulatory mechanism of DAT functions would be used in the developments of curable or preventable methods for cocaine-addict or Parkinsonism, without impairment of normal DAT function. However, the results in this paper indicate that both of dopamine and $\mathrm{MPP}^{+}$transports are modulated by PKC-phosphorylation. It was reported that cocaine binding was also modulated by PMA, although the inhibitory patterns of

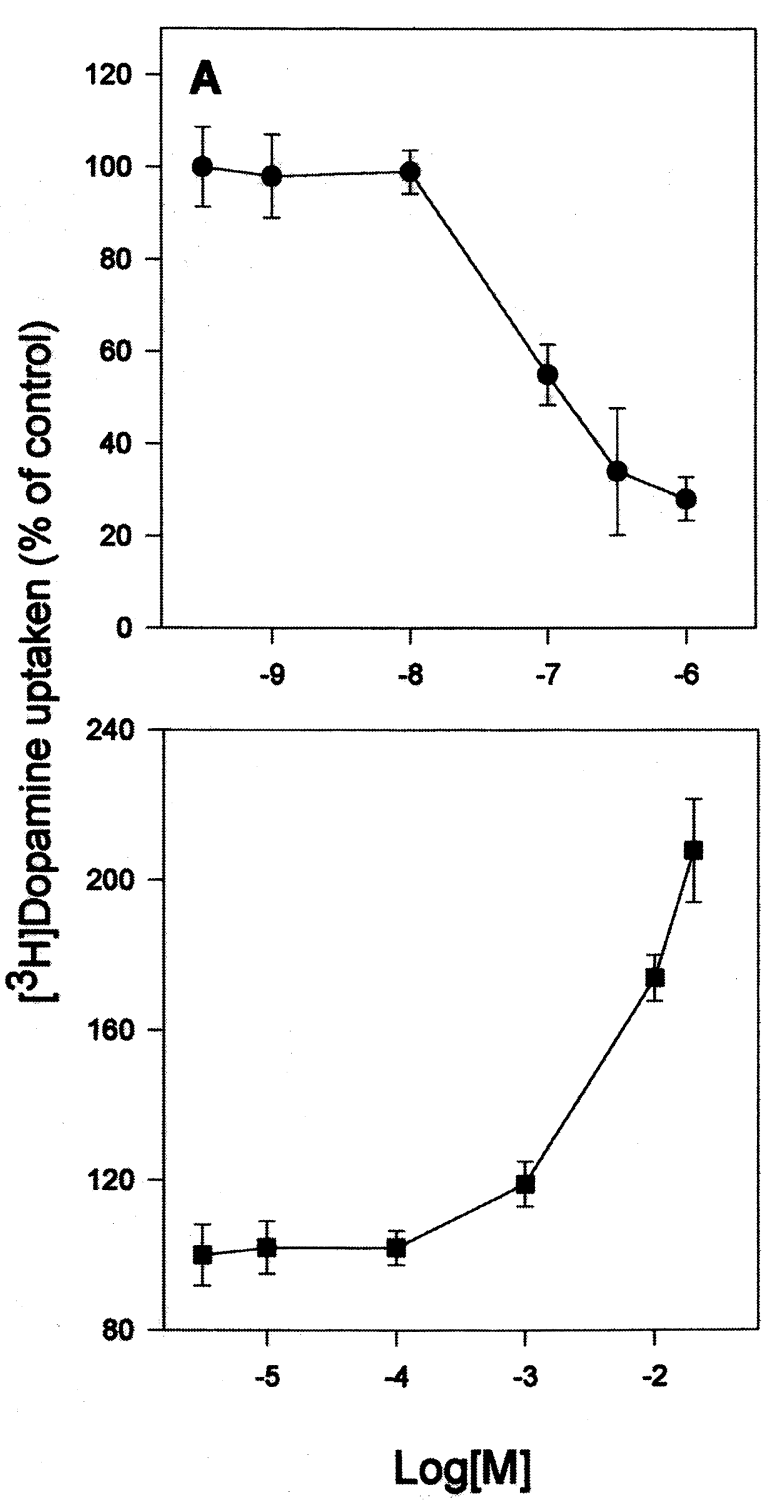

Figure 1. Effects of increasing concentrations of (A) PMA or (B) calphostin $\mathrm{C}$ on dopamine uptake in CV-1 cell expressing pRc/CMVDAT. Cells were preincubated for $10 \mathrm{~min}$ at $37^{\circ} \mathrm{C}$ with PMA (or calphostin $\mathrm{C}$ ) at the indicated concentrations. Transport activity was measured in the presence of $100 \mathrm{nM}\left[{ }^{3} \mathrm{H}\right] \mathrm{D}$ opamine for $10 \mathrm{~min}$ at $37^{\circ} \mathrm{C}$. Values represent means \pm S.D. of three experiments. 


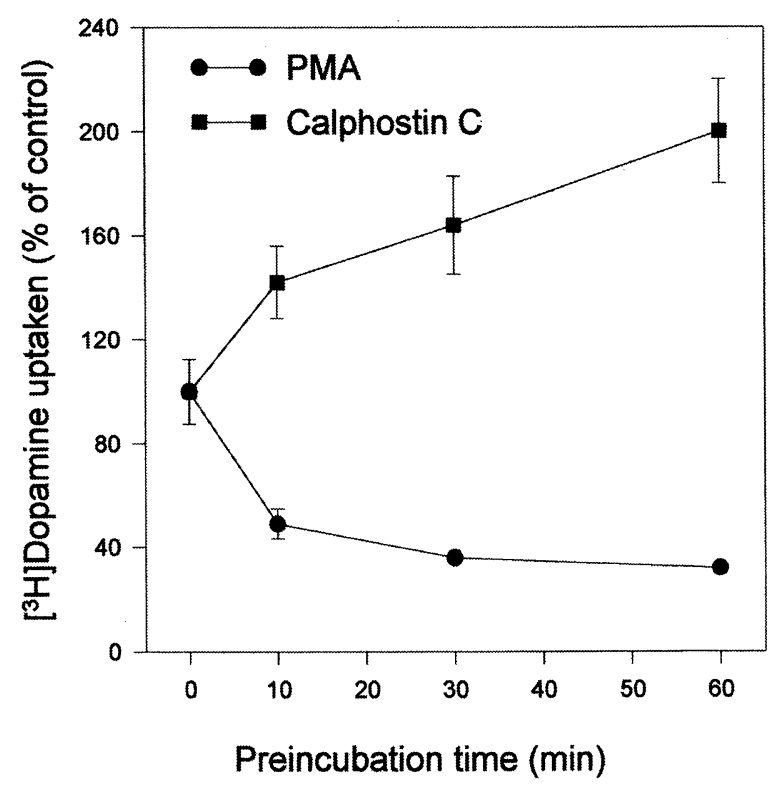

Figure 2. Effects of increasing preincubation-times with PMA or calphostin $\mathrm{C}$ on dopamine uptake in CV-1 cell expressing pRc/CMVDAT. Cells were preincubated with PMA (or calphostin C) for indicated durations at $37^{\circ} \mathrm{C}$, and followed by incubation in the presence of $100 \mathrm{nM}$ $\left[{ }^{3} \mathrm{H}\right]$ dopamine for $10 \mathrm{~min}$ at $37^{\circ} \mathrm{C}$. Values represent means \pm S.D. of three experiments.

PMA on dopamine uptake and cocaine binding are slightly different (Kitayama et al., 1994). These findings suggest that all of the DAT functions are modulated by similar PKC-mediated phosphorylation.

\section{References}

Berridge, M. J. (1984) Inositol triphosphate and diacylglycerol as second messengers. Biochem. J. 220: 345-360

Boja, J. W., Markham, L., Patel, A., Uhl, G. and Kuhar, M. J. (1992) Expression of single dopamine transporter cDNA can confer two cocaine binding sites. NeuroReport 3: 247-248

Brasseur, R., Cabiaux, V., Haurt, P., Castagna, M., Bazter, S. and Ruysschaert, J. M. (1985) Structural analogies between protein kinase C activators. Biochem. Biophys. Res. Commun. 127: 969-976

Cool, D. R., Leiback, F., Bhella, V. K., Mahesh, V. B. and Ganaphathy, V. (1991) Expression and cyclic AMP-dependent regulation of a high affinity serotonin transporter in the human placental choriocarcinoma cell line. J. Biol. Chem. 266: 15750-15757

Casado, M., Zafra, F., Aragon, C. and Gimenez, C. (1991) Activation of high-affinity uptake of glutamate by phorbol esters in primary glial cell cultures. Neurochemistry 57: 1185-1190

Casado, M., Bendahan, A., Zafra, F., Danbolt, N. C., Aragon, C., Gimenez, C. and Kanners, B. I. (1993) Phosphorylation and modulation of brain glutamate transporter by protein kinase C. J. Biol. Chem. 268: 27313-27317

Castagna, M., Takai, Y., Kaibuchi, K., Samo, K., Kikkawa, V. and
Nishizuka, Y. (1982) Direct activation of calcium-activated, phospholipid dependent protein kinase by tumor promoting phorphol esters. J. Biol. Chem. 257: 7847-7857

Exton, J. H. (1990) Signaling through phosphatidylcholine breakdown. J. Biol. Chem. 265: 1-4

Felgner, P. L., Gadek, T. R., Holm, M., Roman, R., Chan, H. W., Wenz, M., Northrop, J. P., Ringold, G. M. and Danielsen, M. (1987) Lipofectin: a highly efficient, lipid-mediated DNA-transfection procedure. Proc. Natl. Acad. Sci. U.S.A. 84: 7413-7417

Kitayama, S., Shimada, S. and Uhl, G. R. (1992a) Parkinsonisminducing neurotoxin MPP+: uptake and toxicity in nonneuronal COS cells expressing dopamine transporter cDNA. Ann. Neurol. 32: 109-111

Kitayama, S., Shimada, S., Xu, H., Markham, L., Donovan, D. M. and Uhl, G. R. (1992b) Dopamine transporter site-directed mutations differentially alter substrate transport and cocaine binding. Proc. Natl. Acad. Sci. U.S.A. 89: $7782-7785$

Kitayama, S., Wang, J., and Uhl, G. R. (1993) Dopamine transporter mutants selectively enhance MPP+ transport. Synapse 15: 58-62

Kitayama, S., Dohi, T. and Uhl, G. R. (1994) Phorbol esters alter functions of the expressed dopamine transporter. Eur. J. Pharmacol. 268: $115-119$

Kobayashi, E., Nakano, H., Morimoto, M. and Tamaoki, T. (1989) Calphostin C, a novel microbial compound, is a highly potent and specific inhibitor of protein kinase C. Biochem. Biophys. Res. Commun. 159: 548-553

Horn, A. S. (1990) Dopamine uptake: a review of progress in the last decade. Prog. Neurobiol. 34: 387-400

Iversen, L. L. (1971) Role of transmitter uptake mechanisms in synaptic neurotransmission. Br. J. Pharmacol. 41: 571-591

Nishizuka, Y. (1984) The role of protein kinase C in cell surface signal transduction and tumor promotion. Nature 308: 693-698

Nishizuka, Y. (1986) Studies and perspectives of protein kinase C. Science 233: 305-312

Shimada, S., Kitayama, S., Lin, C. L., Patel, A., Nanthakumar, E., Gregor, P., Kuhar, M. and Uhl, G. (1991) Cloning and expression of a cocaine-sensitive dopamine transporter compleemntary DNA. Science 254: $576-578$

Snyder, S. H. and D'Amato, R. J. (1986) MPTP: a neurotoxin relevent to the pathophysiology of Parkinson's disease. Neurology 36: 250-258

Tian, Y., Kapatos, G., Granneman, J. G. and Bannon, M. J. (1994) Dopamine and (-aminobutyric acid transporter: differential regulation by agents that promote phosphorylation. Neurosci. Lett. 173: 143-146

Uhl, G. R. (1990) Parkinson's disease: neurotransmitter and neurotoxin receptors and their genes. Eur. Neurol. 30: 21-30

Uhl, G. R. (1992) Neurotransmitter transporters (plus) promising new gene family. Trends Neurosci. 15: 265-268

Uhl, G. R. and Hartig, P. R. (1992) Transporter explosion: update on uptake. Trends Pharmacol. Sci. 13: 421-425

Usdin, T. B., Mezey, E., Chen, C., Brownstein, M. J. and Hoffman, B. J. (1991) Cloning of the cocaine-sensitive bovine dopamine transporter. Proc. Natl. Acad. Sci. U.S.A. 88: 11168-11171 